\title{
Body Image Perceptions and Eating Patterns Among Preadolescent Children
}

\author{
Karen M. Skemp-Arlt and Richard P. Mikat \\ University Wisconsin - La Crosse
}

\begin{abstract}
Preadolescent children are showing patterns of body distortion and unhealthy dieting practices to attempt weight manipulation. The present study examined body image perceptions and interest in weight manipulation among 215 preadolescent children (girls, $n=101$ ) (mean age $=10$ ) in third, fourth, and fifth grades. To measure body image perceptions, children were asked to answer two multiple choice questions: I think I am: fat, skinny, in-between; and I would like to: lose weight, gain weight, stay the same. Interest in weight manipulation was measured using the Children's Eating Attitude Test (ChEAT). Results indicated that children show a fairly accurate perception of their body shape and size and this remained consistent for both genders and across all age groups. ANOVA results showed children who felt they were "fat" had a significantly higher level of disturbed eating patterns (ChEAT mean $=14.00$ ) compared to the children who felt they were "in-between" (ChEAT mean $=6.95)(p=.009)$. Children who indicated they would like to "lose weight" had significantly higher ChEAT scores (mean = 9.19) than those who wanted to "stay the same" (mean = 6.56) $(\mathrm{p}=.033)$. ChEAT scores for girls showed a significant difference between the "fat" group $($ mean $=29.00)$ and the "in-between" group (mean $=6.81)$ $(p<.001)$ and between the "fat" group and the "skinny" group (mean $=10.78)(p=.002)$. Twenty-five percent of this sample of children indicated a desire to "lose weight" (mean body mass index $=21.35$ ) and $67 \%$ desired to "stay the same" (mean body mass index $=17.45$ ). Preadolescent children are showing a desire for a thinner body type and are already developing a motivation to avoid weight gain or obesity through dietary manipulation. Early identification of body distortion and disturbed eating patterns could help with education and prevention strategies.
\end{abstract}

(c) 2007 Californian Journal of Health Promotion. All rights reserved.

Keywords: preadolescent children, body image, eating behaviors, dieting

\section{Introduction}

Modern western culture emphasizes a thin body shape for women and a muscular physique for men. In response to this growing cultural norm, young adults and adolescents often turn to unhealthy eating patterns and frequent dieting practices in order to control their weight or transform their bodies into what they consider the ideal body shape or size of their culture. Roughly $70 \%$ of women over the age of thirteen routinely cycle on and off of various weight-loss plans and many young men are showing common trends (Cohane and Pope, 2001; Kater, 2006). Adolescent girls are the most vulnerable population when it comes to dieting, unhealthy eating patterns, and clinical eating disorders. Studies have shown that as many as $70 \%$ of normal weight adolescent girls feel fat and are engaging in unhealthy eating practices for the purpose of losing weight (Kater, Rohwer, and Levine, 2000). Six percent of adolescent girls will progress from "normal" dieting to a subthreshold or diagnosable eating disorder (Kater, Rohwer, and Levine, 2000). Furthermore, Mensinger (2005) found that approximately 56\% of female public school students in Minnesota are evidencing problematic eating behaviors. While at the same time, young male adolescents are turning toward unhealthy eating practices so as to lose or gain weight (Cohane and Pope, 2001).

Several precipitants of disordered or disturbed eating patterns have been noted in the literature. Low self-esteem, poor body image, peer influences, and cultural messages are among the 
most frequently cited, particularly among the adolescent population (Herbozo, Tantleff-Dunn, Gokee-Larose and Thompson, 2004; Hill and Pallin, 1998; Lieberman, Gauvin, Bukowski, and White, 2001; Littleton and Ollendick, 2003; Neumark-Sztainer, Story, Hannan, Beuhring, and Resnick, 2000; Skemp-Arlt, 2006). Recent research has turned toward investigating the development of this dieting preoccupation and unhealthy eating patterns among preadolescent children (Maloney, McGuire, Daniels, and Specker, 1989; Serdula, Collins,Williamson, Anda, Pamuk, and Byers, 1993, Kostanske and Gullone, 1999). Alarmingly, studies show that dieting is a 'normal' eating style for many young girls, as well as boys, even though oftentimes the body mass index (BMI) of these children indicate that they are already underweight (Hill, Draper, and Stack, 1994; Shapiro, Newcombe, and Loeb, 1997). A desire for thinness was evident in a recent investigation by Schur, Sanders, and Steiner (2000). They found that $42 \%$ of the girls and $36 \%$ of the boys in grades one through three desired a thinner body shape. Furthermore, they found that $52 \%$ of the girls and $48 \%$ of the boys wanted to lose weight. More recently, in a study of children ages eight to ten years old, Skemp-Arlt, Rees, Mikat, and Seebach (2006) found that $50 \%$ of the girls were dissatisfied with their current body shape, with $45 \%$ wishing to be thinner. Boys showed similar trends, with 49\% dissatisfied and 39\% wishing to be thinner.

Clearly, the desire for an ideal body weight and shape exists among the preadolescent population. More surprising is the interest and practice of manipulating body weight and shape through unhealthy eating practices to attain an ideal. The main purpose of this study, therefore, was to investigate whether children in third, fourth, and fifth grades perceive their body shape and size in an accurate fashion. Secondly, the investigators were interested in determining what types of eating patterns exist among this age group. Finally, the investigators sought to determine if there was evidence of the emergence of abnormal eating patterns to manipulate weight among this age group.

\section{Method}

\section{Subjects}

Participants included 215 pre-adolescent children from one public $(\mathrm{n}=74$, females $=34)$ and six parochial $(\mathrm{n}=141$, females=67) Wisconsin schools. Permission to participate in the study was obtained through letters to parents. All procedures were approved by the Institutional Review Board (IRB) for the Protection of Human Subjects at the University of Wisconsin-La Crosse. Permission was also obtained from the participating public school district's research and development team. Consent from the parochial schools was obtained from the administration from each participating school. The sample consisted of female $(n=101)$ and male $(n=114)$ children from third $(n=74)$, fourth $(n=60)$, and fifth $(n=81)$ grades. These particular grades were selected for two reasons: 1) body distortion and disturbed eating patterns increase during adolescence, particularly among girls; so the present study sought to determine if these occur prior to adolescence; and 2) the language used in the assessment tool was thought to be too difficult to comprehend if the children were any younger than third grade. The average age of the participants was ten years. The average body mass index (BMI) for the girls was $18.06 \pm 2.63$ and the average BMI for the boys was $18.59 \pm$ 3.20 .

\section{Instrumentation}

The children's version of the Eating Attitudes Test (ChEAT) was used to measure participants' attitudes and behaviors concerning eating. The ChEAT is a simplified version of the Eating Attitude Test developed by Garfinkel and Garner (1982). It has been used in previous studies and has been shown to be a reliable and valid tool for measuring eating attitudes among children younger than 15 years of age (Kelly, Ricciardelli, and Clarke, 1999; Maloney, McGuire, and Daniels 1988; Rolland, Farnill, and Griffiths, 1998; Smolak and Levine, 1994). This survey consists of 26 questions and is based on a Likert scale from 1 (always) to 6 (never). For each question, the most symptomatic response as indicated by the answer "always" is recoded as a score of three, the next most symptomatic response as indicated by an answer 
of "very often" is recoded as a score of two and the third most symptomatic response as indicated by an answer of "often" is recoded as a score of one. The remaining responses ("sometimes", "rarely", and "never") receive a score of zero. This method of scoring was adapted from previous research by Maloney et al. (1989) and represents a "symptomatic score." When using the symptomatic scoring, Maloney et al. (1989) established that a score of $\geq 20$ indicated abnormal eating patterns. This score was used as a cutoff score by Garner, Olmsted, Bohr, and Garfinkel (1982) in adult samples. Using the sum of Likert scale values, ChEAT scores can range from 0-78.

\section{Procedure}

To measure body image perceptions, the investigator met one on one with each child. The child was asked to answer two multiple choice questions read aloud to them by the investigator.

1. Self: I think I am: fat, skinny, in-between

2. Ideal Self: I would like to: lose weight, gain weight, stay the same.

Height and weight were recorded by a second investigator using portable scales and tape measures, with BMI rankings subsequently calculated and assigned according to the Centers for Disease Control and Prevention (2005) guidelines.

The ChEAT surveys were administered to the participants by their classroom teachers. The teachers read each question aloud to the participants and waited briefly for all to complete the answer before moving on to the next question. The classroom teachers then collected the surveys and removed any form of identification associated with the completed surveys so as to maintain confidentiality. (This method of data collection was recommended by the university's IRB so that any child who may have indicated more serious eating disturbances could be identified by the classroom teacher and could then receive any assistance or referral if necessary.) The investigator then collected the completed surveys from the participating schools.

\section{Data Analysis}

Data were entered and analyzed using the Statistical Package for Social Sciences (SPSS) version 12.0. The symptomatic scoring scale was used as a measure of eating patterns among the groups. A score of $\geq 20$ was used to identify significantly abnormal eating patterns as recommended in previous research (Garner et al., 1982). A 3 X 3 Factorial Analysis of Variance was used to examine differences in ChEAT scores between perception of self categories (fat, skinny, and in-between) and interest in weight manipulation categories (lose weight, gain weight, and stay the same). The significance level was set at .05.

\section{Results}

A 2 X 3 factorial analysis of variance on ChEAT scores showed no significant differences between boys and girls $(\mathrm{F}=.852, \mathrm{p}=.357)$ or between grades three, four, and five $(\mathrm{F}=2.47$, $\mathrm{p}$ $=.087)$. There was no significant interaction effect between gender and grade $(F=.55, p=$ $.578)$.

The average BMI for all of the girls in the present study was $18.06 \pm 2.63$. According to the growth charts for height to weight (BMI forage-percentiles) from the Center for Disease Control and Prevention (2005), this is below the 75th percentile for a ten year old. The average BMI for all of the boys was $18.59 \pm 3.20$, which falls below the 85th percentile. By definition, a child is classified as obese if his or her BMI falls at or above the 95th percentile and is at risk of becoming overweight or obese if his or her BMI falls between the 85th and 95th percentile (CDC and $\mathrm{P}, 2005)$. On average, the children who participated in the present study fell within the normal weight range for their age and gender.

Four percent of the children felt they were "fat", $19 \%$ felt they were "skinny", and 77\% felt they were "in-between". Further, 25\% of the children indicated they would like to "lose weight", 7\% indicated they would like to "gain weight" and $67 \%$ indicated they would like to "stay the same”.

Mean ChEAT scores and standard deviations for the three "I think I am" groups are shown in 
Table 1. ANOVA results indicated a statistically significant difference between groups $(\mathrm{F}=$ 3.571, $\mathrm{p}=.03$ ). Tukey Post Hoc comparisons indicated a statistically significant difference between the "fat" group (mean = 14.00) and the “in-between” group (mean = 6.95) $(\mathrm{p}=.009)$. There were no statistically significant differences between the other groups. Mean body mass index (BMI) for each "I think I am" group are presented in Table 2 .

Table 1

Mean ChEAT scores among “I think I am” groups

\begin{tabular}{|l|c|c|c|c|c|c|}
\hline I think I am & $\begin{array}{c}\text { Mean ChEAT } \\
\text { Score (All) }\end{array}$ & $\begin{array}{c}\text { Mean ChEAT } \\
\text { score (Girls) }\end{array}$ & $\begin{array}{c}\text { Mean ChEAT } \\
\text { Score (Boys) }\end{array}$ & $\begin{array}{c}\text { SD } \\
\text { (All) }\end{array}$ & $\begin{array}{c}\text { SD } \\
\text { (Girls) }\end{array}$ & $\begin{array}{c}\text { SD } \\
\text { (Boys) }\end{array}$ \\
\hline Fat & $14.00^{1}$ & $29.00^{2,3}$ & 9.00 & 14.51 & 25.46 & 6.72 \\
\hline Skinny & 8.36 & $10.78^{3}$ & 6.54 & 7.23 & 8.82 & 5.26 \\
\hline In between & $6.95^{1}$ & $6.81^{2}$ & 7.08 & 6.02 & 6.24 & 5.79 \\
\hline
\end{tabular}

$$
{ }^{1} \mathrm{p}=.009 ;{ }^{2} \mathrm{p}<.001 ;{ }^{3} \mathrm{p}=.002
$$

Table 2

Mean BMIs for the "I think I am” groups

\begin{tabular}{|l|c|c|c|c|c|c|}
\hline I think I am & $\begin{array}{c}\text { Mean BMI } \\
\text { (All) }\end{array}$ & $\begin{array}{c}\text { Mean BMI } \\
\text { (Girls) }\end{array}$ & $\begin{array}{c}\text { Mean BMI } \\
\text { (Boys) }\end{array}$ & $\begin{array}{c}\text { SD } \\
\text { (All) }\end{array}$ & $\begin{array}{c}\text { SD } \\
\text { (Girls) }\end{array}$ & $\begin{array}{c}\text { SD } \\
\text { (Boys) }\end{array}$ \\
\hline Fat & 25.51 & 24.04 & 26.00 & 2.51 & 3.62 & 2.25 \\
\hline Skinny & 16.28 & 16.00 & 16.49 & 1.80 & 2.04 & 1.60 \\
\hline In between & 18.52 & 18.37 & 18.56 & 2.58 & 2.37 & 2.77 \\
\hline
\end{tabular}

Mean ChEAT scores and standard deviations for the three "I would like to" groups are shown in Table 3. ANOVA results indicated a statistically significant difference between groups $(\mathrm{F}=$ 5.226, $\mathrm{p}=$.006). Tukey Post Hoc comparisons indicated a statistically significant difference between the "lose weight" group (mean = 9.19) and the "stay the same" group (mean = 6.56) (p $=.033$ ). There were no statistically significant differences between the other groups. Mean body mass index (BMI) for each "I would like to" group are presented in Table 4.

Table 3

Mean ChEAT scores among the "I would like to" groups

\begin{tabular}{|l|c|c|c|c|c|c|}
\hline I would like to & $\begin{array}{c}\text { Mean ChEAT } \\
\text { score (All) }\end{array}$ & $\begin{array}{c}\text { Mean ChEAT } \\
\text { score (Girls) }\end{array}$ & $\begin{array}{c}\text { Mean ChEAT } \\
\text { Score (Boys) }\end{array}$ & $\begin{array}{c}\text { SD } \\
\text { (All) }\end{array}$ & $\begin{array}{c}\text { SD } \\
\text { (Girls) }\end{array}$ & $\begin{array}{c}\text { SD } \\
\text { (Boys) }\end{array}$ \\
\hline Lose Weight & $9.19^{1}$ & 9.80 & 8.42 & 8.09 & 9.53 & 5.92 \\
\hline Gain Weight & 10.19 & $17.00^{2}$ & 8.62 & 9.12 & 16.00 & 6.86 \\
\hline Stay the Same & $6.56^{1}$ & $6.75^{2}$ & 6.39 & 5.82 & 6.33 & 5.37 \\
\hline
\end{tabular}

${ }^{1} \mathrm{p}=.033 ;{ }^{2} \mathrm{p}=.033$ 
Table 4

Mean BMIs for the "I would like to" groups

\begin{tabular}{|l|c|c|c|c|c|c|}
\hline I would like to & $\begin{array}{c}\text { Mean BMI } \\
\text { (All) }\end{array}$ & $\begin{array}{c}\text { Mean BMI } \\
\text { (Girls) }\end{array}$ & $\begin{array}{c}\text { Mean BMI } \\
\text { (Boys) }\end{array}$ & $\begin{array}{c}\text { SD } \\
\text { (All) }\end{array}$ & $\begin{array}{c}\text { SD } \\
\text { (Girls) }\end{array}$ & $\begin{array}{c}\text { SD } \\
\text { (Boys) }\end{array}$ \\
\hline Lose weight & 21.35 & 20.78 & 22.06 & 2.86 & 2.36 & 3.29 \\
\hline Gain weight & 16.23 & 13.89 & 16.76 & 2.10 & 0.53 & 1.95 \\
\hline Stay the same & 17.45 & 17.05 & 17.81 & 2.19 & 1.66 & 2.52 \\
\hline
\end{tabular}

When analyzing the results of the girls and boys separately, two \% of the girls felt they were "fat", $18 \%$ felt they were "skinny", and $80 \%$ felt they were "in-between". In regards to the girls' level of interest in weight manipulation, $29 \%$ indicated they would like to "lose weight", 3\% indicated they would like to "gain weight" and $67 \%$ indicated they would like to "stay the same". For the boys, five \% felt they were "fat", $21 \%$ felt they were "skinny", and $74 \%$ felt they were "in-between". For the boys' level of interest in weight manipulation, 21\% indicated they would like to "lose weight", $11 \%$ indicated they would like to "gain weight" and 68\% indicated they would like to "stay the same".

Mean ChEAT scores and standard deviations for the three "I think I am" groups for the girls are shown in Table 1. ANOVA results indicated a statistically significant difference between groups $(\mathrm{F}=14.038, \mathrm{p}<.001)$. Tukey Post Hoc comparisons indicated a statistically significant difference between the "fat" group (mean = 29.00) and the "in-between" group (mean = $6.81)(\mathrm{p}<.001)$ and between the "fat" group and the "skinny" group $($ mean $=10.78)(p=.002)$. There were no statistically significant differences between the "skinny" and "inbetween" groups.

Mean Body Mass Index (BMI) for each "I think I am" group for the girls are presented in Table 2.
Mean ChEAT scores and standard deviations for the three "I would like to" groups for the girls are shown in Table 3. ANOVA results indicated a statistically significant difference between groups $(\mathrm{F}=3.636, \mathrm{p}=.03)$. Tukey Post Hoc comparisons indicated a statistically significant difference between the "gain weight" group (mean $=17.00)$ and the "stay the same" group $($ mean $=6.75)(p=.033)$. There were no statistically significant differences between the other groups.

Mean ChEAT scores and standard deviations for the three "I think I am" groups for the boys are shown in Table 1. ANOVA results indicated no statistically significant difference between groups. Mean Body Mass Index (BMI) for each "I think I am" group for the boys are presented in Table 2.

Mean ChEAT scores and standard deviations for the three "I would like to" groups for the boys are shown in Table 3. ANOVA results indicated no statistically significant difference between groups.

Nine children scored above the 20-point cutoff. This represents $4.41 \%$ of the sample. Table 5 shows specific ChEAT scores and BMIs for these children.

Table 5

Clinical ChEAT scores

\begin{tabular}{|l|c|c|c|c|c|}
\hline Gender & Count & ChEAT Mean & ChEAT SD & BMI Mean & BMI SD \\
\hline Girls & 6 & 32.83 & 8.09 & 19.75 & 4.49 \\
\hline Boys & 3 & 26.33 & 4.14 & 18.09 & 4.85 \\
\hline
\end{tabular}




\section{Discussion}

The literature suggests that preadolescent children are showing an interest in a thin body type and are engaging in disturbed or abnormal eating patterns to achieve this ideal. Preadolescent children as young as 7 years old are showing dietary behaviors that were once associated with adolescents and adults (Maloney, McGuire, Daniels, and Specker, 1989; Kostanski and Gullone, 1999; Krahnstoever Davison, Markey, and Birch, 2003). The present study found similar results in that third, fourth, and fifth grade children are indeed indicating an interest in becoming and/or remaining thin. Furthermore, while most participants in this study had ChEAT scores below the cutoff score of 20, children who felt they were "fat" reflected a higher level of disturbed eating patterns compared to the children who felt they were "skinny" or "inbetween.”

Body image distortion is a common trend that is increasing among children and adolescents. Body image distortion occurs when an individual perceives his or her body shape and size in an inaccurate fashion. Body image distortion peaks during early adolescence, particularly among women. In one study, Greenfield, Quinlan, Harding, Glass, and Bliss (1987) sampled over 700 high school age girls and boys. From this sample, 81 percent of the girls and 26 percent of the boys stated that they often felt fat. Body image distortion was distinct among the girls, with $46 \%$ describing themselves as overweight, when in fact only $12 \%$ were. The present study's results, however, indicated that preadolescent children showed a fairly accurate perception of their body shape and weight. In other words, children who felt they were "fat" had BMIs of 25.51, "skinny" had BMI's of 16.28, and "in-between" had BMIs of 18.52. According to the Center for Disease Control and Prevention (2005), a BMI greater than 24 for this age group would place the child above the 97th percentile, or classified as "obese." A BMI of 16.28 falls below the 50th percentile for both genders and a BMI of 18.52 falls at or below the 75th percentile for boys and girls, respectively. Therefore, in contrast to other studies, these results show that body distortion is not yet evident with this group of preadolescent children.

Twenty-five percent of this sample of children indicated a desire to "lose weight." These children had BMIs of 21.35, which placed them above the 90th percentile (or "overweight") for this age group. Perhaps more striking was the number of children (67\%) who desired to "stay the same." The average BMI for this group of children was 17.45, which falls below the 75th percentile and is considered "normal" body weight for this age group. Based on these results, these preadolescent children are showing a desire for a thinner body type and perhaps are already developing a motivation to avoid weight gain or obesity and the negative stereotypes associated with it. It is well documented in the literature that overweight or obese children are less likeable and less popular than their normal weight peers (Hendy, Gustitus, LeitzelSchwalm, 2001). Furthermore, one might surmise that cultural messages regarding an ideal body type as well as messages to transform one's body into this ideal shape or size through dietary manipulation are reaching these preadolescent children. Edelman (1982) found that even children as young as five years of age realize a relationship between eating and obesity. As such, dietary restraint or manipulation could manifest at an early age.

When looking at the results of boys and girls separately, there was a greater difference between groups among the girls than among the boys. The boys showed accurate body perception across all groups ("fat”, "skinny", and "in-between"). Moreover, ChEAT scores among the boys remained consistent across all groups ("lose weight", "gain weight", "stay the same”). Not surprisingly, a greater percentage of boys (11\%) showed an interest in gaining weight than did the girls (3\%). Studies support that women, particularly white women, show a strong desire for thinness regardless of age or despite being of normal weight, while men on the other hand are more likely to express a desire for a more muscular physique. In general, boys develop an interest in developing a more muscular physique as they approach the age of 11 years (Smolak, 2004). 
The girls also demonstrated fairly accurate body perceptions across all groups ("fat", "skinny", and "in-between"). On the other hand, the girls who felt they were "fat" scored very high ChEAT scores (mean $=29.00$ ) indicating abnormal or disturbed eating patterns. Research indicates that children who show weight concerns at an early age will likely engage in dietary restraint before early adolescence (Krahnstoever Davison, Markey, and Birch, 2003). These results represent only a small percentage of the female participants (2\%), however, any indication of disturbed eating patterns among preadolescents is of concern. Similar research by Kostanske and Gullone (1999) found that children as young as seven years of age were engaging in restrictive dieting practices. These authors state that children who seriously restrict energy intake are at great risk of developing physical ailments, such as cardiac arrhythmias, renal failure, and gastric rupture as well as inhibit cognitive functioning and retard intellectual development. Furthermore, in girls, excessive dieting can disrupt the onset of menarche, retard breast development, and permanently stunt physical growth.

Nine children in the present study scored above the 20 point cutoff, indicating a very high level of disturbed eating patterns. This represents $4.41 \%$ of the sample of eight- to ten-year-old children, which is approaching reported percentages of adolescent eating disorders of $6 \%$ (Kater, Rohwer, and Levine, 2000). Similar to previous research, Maloney et al. (1989) found $6.9 \%$ of children in third through sixth grades had ChEAT scores in the "anorexia nervosa range” ( $\geq 20)$. Despite this small percentage, children are showing more serious signs of disturbed, if not clinically dangerous eating patterns. As such, education and prevention strategies are certainly indicated for preadolescent children.

It is noted in the literature that concern with body image as well as preoccupation with dieting and weight manipulation increases as children approach adolescence. Contrary to this, trends are not really developing across age levels with this group of children. However, results do indicate the early emergence of desiring a certain body type and manipulating eating patterns so as to strive for this body type. This is similar to the recent studies which find that young children are showing body image dissatisfaction and atypical eating attitudes prior to adolescence (Kostanski and Gullone, 1999; Maloney, McGuire, Daniels, and Specker, 1989; Rolland, Farnill, and Griffiths, 1998). Dietary manipulation to achieve or maintain weight has been associated with more severe eating disorders (Patton, Selzer, Coffey, Carlin, and Wolfe, 1999). Therefore, early identification of dieting behaviors may lead to more successful interventions.

\section{Limitations}

Parental consent was obtained for all children who participated in this study. This may have caused a selection bias in the sample of participating children. It is believed that parents who did not give consent may have denied participation because their child was overweight or underweight and did not want to bring further attention to their body shape, size, or dieting practices. This speculation was supported by informal comments from parents and teachers to the researcher. Furthermore, the participating schools consisted mostly of Caucasian, middle class students. Therefore, generalization of results to a larger, more diverse sample of children may be problematic.

\section{Conclusion}

Overall results of this study were encouraging, in that this group of children had healthy and accurate body perceptions. This remained consistent across age groups. On the other hand, despite this positive finding, children as young as eight years of age are showing an interest in weight manipulation or a desire to lose weight. This was common among both genders. An interest in weight loss generally leads to abnormal eating patterns. Some of these children, particularly the girls, indicated atypical or problematic eating behaviors. Early prevention strategies are recommended for children prior to adolescence. Emphasis should be placed on empowering preadolescent children to recognize and resist the cultural messages that they are exposed to. Furthermore, teaching children about what their bodies will experience 
during puberty may help them to develop greater body esteem as well as an appreciation for body differences. This may serve as an antidote to the drive for thinness, perfection, and flawless faux beauty they are exposed to on a daily basis.

\section{References}

Centers for Disease Control and Prevention, National Center for Health Statistics (February 12, 2007). 2000 CDC growth charts. Retrieved March 1, 2007, from http://www.cdc.gov/growthcharts/

Cohane, G. H., \& Pope, Jr., H. G. (2001). Body image in boys: A review of the literature. International Journal of Eating Disorders, 29, 373-379.

Edelman, B. (1982). Developmental differences in the conceptualization of obesity. Journal of the American Dietetic Association, 80, 122-127.

Garfinkel, P. E., \& Garner, D. M. (1982). Anorexia nervosa: A multidimensional perspective. New York: Brunner Mazel.

Garner, D., Olmsted, M. P., Bohr, Y., \& Garfinkel, P. (1982). The eating attitudes test: Psychometric features and clinical correlates. Psychological Medicine, 12, 871-878.

Greenfield, D., Quinlan, D. M., Harding, P., Glass, E., \& Bliss, A. (1987). Eating behavior in an adolescent population. International Journal of Eating Disorders, 6, 99-111.

Hendy, H. M., Gustitus, C., Leitzel-Schwalm, J. (2001). Social cognitive predictors of body image in preschool children. Sex Roles, 44, 557-569.

Herbozo, S., Tantleff-Dunn, S., Gokee-Larose, J., \& Thompson, K. J. (2004). Beauty and thinness messages in children's media: A content analysis. Eating Disorders, 12, 21-34.

Hill, A. J., Draper, E., \& Stack, J. (1994). A weight on children’s minds: Body shape dissatisfactions at 9years-old. International Journal of Obesity, 18, 383-389.

Hill, A. J., \& Pallin, V. (1998). Dieting awareness and low self-worth: Related issues in 8-year-old girls. International Journal of Eating Disorders, 24, 405-413.

Kater, K. J. (2006). Promotion of healthy weight: Helping without harming. Synergy Learning, 22-23.

Kater, K. J., Rohwer, J., \& Levine, M. P. (2000). An elementary school project for developing healthy body image and reducing the risk factors for unhealthy and disordered eating. Eating Disorders, 3-15.

Kelly, C., Ricciardelli, L. A., \& Clarke, J. D. (1999). Problem eating attitudes and behaviors in young children. Journal of Eating Disorders, 25, 281-286.

Kostanske, M, \& Gullone, E. (1999). Dieting and body image in the child's world: Conceptualization and behavior. The Journal of Genetic Psychology, 160, 488-499.

Krahnstoever Davison, K., Markey, C. N., \& Birch, L. L. (2003). A longitudinal examination of patterns in girls' weight concerns and body dissatisfaction from ages 5 to 9 years. International Journal of Eating Disorders, 33, 320-332.

Lieberman, M., Gauvin, L., Bukowski, W. M., \& White, D. R. (2001). Interpersonal influence and disordered eating behaviors in adolescent girls. The role of peer modeling, social reinforcement, and body related teasing. Eating Behaviors, 2, 215-236.

Littleton, H. L., \& Ollendick, T. (2003). Negative body image and disordered eating behavior in children and adolescents: What places youth at risk and how can these problems be prevented? Clinical Child and Family Psychology Review, 6, 51-66.

Maloney, M. J., McGuire, J., Daniels, S. R., \& Specker, B. (1989). Dieting behavior and eating attitudes in children. Pediatrics, 84, 482-489.

Maloney, M. J., McGuire, J., Daniels, S. R. (1988). Reliability testing of a children's version of the eating attitude test. Journal of American Academy of Child and Adolescent Psychiatry, 27(5), 541-543.

Mensinger, J. L. (2005). Disordered eating and gender socialization in independent-school environments. Journal of Ambulatory Care Management, 28(1), 30-40.

Neumark-Sztainer, D., Story, M., Hannan, P. J., Beuhring, T., \& Resnick, M. D. (2000). Disordered eating among adolescents: Associations with sexual/physical abuse and other familial/psychosocial factors. International Journal of Eating Disorders, 28, 249-258. 
Patton, G. C., Selzer, R., Coffey, C., Carlin, J. B. \& Wolfe, R. (1999). Onset of adolescent eating disorders: Population based cohort study over 3 years. British Medical Journal, 318, 765-768.

Rolland, K., Farnill, D., \& Griffiths, R. A. (1998). Eating attitudes and the body mass index of Australian schoolchildren aged 8 to 12 years. European Eating Disorders Review, 6(2), 107-114.

Schur, E.A., Sanders, M., \& Steiner, H. (2000). Body dissatisfaction and dieting in young children. International Journal of Eating Disorders, 27, 74-82.

Serdula, M. K., Collins, M. E., Williamson, D. F., Anda, R. F., Pamuk, E., \& Byers, T. E. (1993). Weight control practices in adolescents and adults. Annals of Internal Medicine, 119, 667-671.

Shapiro, S., Newcomb, M., \& Loeb, T. B. (1997). Fear of fat, disregulated-restrained eating, and bodyesteem: Prevalence and gender differences among eight to ten year old children. Journal of Clinical Child Psychology, 26, 358-365.

Skemp-Arlt, K. M. (2006). Body image dissatisfaction and eating disturbances among children and adolescents: Prevalence, risk factors, and prevention strategies. Journal of Physical Education Recreation and Dance, 77(1), 45-51.

Skemp-Arlt, K. M., Rees, K. S., Mikat, R. P., \& Seebach, E. E. (2006). Body image dissatisfaction among third, fourth, and fifth grade children. Californian Journal of Health Promotion, 4(3), 58-67.

Smolak, L. (2004). Body image in children and adolescents: Where do we go from here? Body Image, 1, 15-28.

Smolak, L., \& Levine, M. (1994). Psychometric properties of the children's eating attitudes test. International Journal of Eating Disorders, 16(3), 275-282.

\author{
Author Information \\ Karen M. Skemp-Arlt, Ph.D.* \\ Assistant Professor \\ Exercise and Sport Science Department \\ 134 Mitchell Hall \\ University Wisconsin - La Crosse \\ 1725 State Street \\ La Crosse, WI 54601 \\ Ph.: 608-785-8187 \\ Fax.: 608-785-8173 \\ E-Mail: skemp.kare@uwlax.edu \\ Richard P. Mikat, Ph.D. \\ Professor \\ Exercise and Sport Science Department \\ 129 Mitchell Hall \\ University Wisconsin - La Crosse \\ 1725 State Street \\ La Crosse, WI 54601 \\ Ph.: 608-785-8177 \\ Fax.: 608-785-8173 \\ E-Mail: Mikat.rich@uwlax.edu \\ * corresponding author
}

